\title{
Development of a MOX equivalence Python code package for ANICCA
}

\author{
Bart Vermeeren* and Hubert Druenne \\ Tractebel (ENGIE), Boulevard Simón Bólivar 34-36, 1000 Brussels, Belgium
}

Received: 15 July 2021 / Received in final form: 15 October 2021 / Accepted: 10 November 2021

\begin{abstract}
The basis of the MOX (Mixed OXide) energy equivalence principle is keeping the in-core fuel management characteristics (cycle length, feed size, etc.) of a nuclear reactor unchanged when replacing UOX (Uranium OXide) fuel assemblies by MOX. If the effect of the loading pattern is neglected, such an equivalence is obtained by tuning the $\mathrm{Pu}$ content in the MOX fuel, while considering the specific $\mathrm{Pu}$ isotopic vector at the time of the core reload to obtain a crossing of the reactivity curves of UOX and MOX at the end-of-cycle core average burnup. It is proposed in this work to extend the fuel cycle analysis tool ANICCA (Advanced Nuclear Inventory Cycle Code) with a MOX equivalence Python code package, which automatically governs the supply and demand of $\mathrm{Pu}$ vector isotopes required to obtain MOX equivalence. This code package can determine the reactivity evolution for any given $\mathrm{Pu}$ vector by means of a multidimensional interpolation on a directive grid of pre-calculated data tables generated by WIMS10, covering the physically accessible $\mathrm{Pu}$ vector space. A fuel cycle scenario will be assessed for a representative evolution of the $\mathrm{Pu}$ vector inventory available in spent UOX fuel as a demonstration case, defining the interim fuel storage building dimensional requirements for different reprocessing strategies.
\end{abstract}

\section{Introduction}

The nuclear fuel cycle is the progression of nuclear fuel through a series of stages: a front-end stage, during which fissile material is mined, enriched and/or reprocessed, and fabricated into fuel assemblies; an operational stage in which the fuel is irradiated in a nuclear reactor; and a back-end stage which serves to either reprocess (closed fuel cycle) or to safely dispose of (open fuel cycle) the spent fuel. A closed fuel cycle is typically more attractive than an open fuel cycle in terms of uranium consumption and waste disposal footprint, but also more demanding in terms of added process complexity associated to fuel reprocessing, heat and radio-toxicity constraints related to fuel transportation and proliferation risks when dealing with purified streams of sensitive nuclear materials.

After a long period of once-through operation of a country's nuclear reactor fleet, substantial quantities of spent UOX (Uranium OXide) fuel assemblies can accumulate in the interim storage buildings over time; e.g. about 1600 assemblies for a typical 1000 MWe PWR-type (Pressurised Water Reactor) nuclear power plant after 40 years of operation in 18-month cycles. A scenario could be envisioned in which after many decades the choice is made to transition,

\footnotetext{
"e-mail: bart.vermeeren@tractebel.engie.com
}

e.g. in order to reduce the need for interim spent fuel storage, from operation in an open fuel cycle to a (partially) closed fuel cycle. This can be done by means of the reprocessing of spent UOX fuel and recycling the $\mathrm{Pu}$ recovered from this reprocessing. The recycling of $\mathrm{Pu}$ can be performed in the form of MOX (Mixed OXide) fuel in LWRs (Light Water Reactors). MOX fuel is a homogeneous mixture of $\mathrm{PuO}_{2}$ and $\mathrm{UO}_{2}$, where $\mathrm{UO}_{2}$ is typically depleted $\mathrm{U}$ originating from the tails of the enrichment process. MOX recycling is generally performed in a justin-time scheme in order to limit the degradation of the $\mathrm{Pu}$ vector by the decay of ${ }^{241} \mathrm{Pu}$ (a fissile isotope) into ${ }^{241} \mathrm{Am}$ (a neutron absorber). Such a scheme requires that the right amount of spent UOX fuel is sent to the reprocessing in order to get in return the right amount of $\mathrm{Pu}$ for the MOX fuel fabrication according to the $\mathrm{Pu}$ isotopy and equivalence objective. Therefore, the production of MOX fuel assemblies for nuclear power plants finds its place in a fuel cycle closure strategy that optimises the use of the fuel resources. The choice of reprocessing strategy will be a defining parameter governing the evolution of the spent fuel inventory over time and hence the size of the interim storage. Adopting a FIFO (First In, First Out) or LIFO (Last In, First Out) strategy for the extraction of spent UOX assemblies from the existing stockpile 
will set the rate at which interim storage buildings will be emptied and dimension the requirements in terms of storage capacity.

It is proposed in this work to extend ANICCA (Advanced Nuclear Inventory Cycle Code) [1], a fuel cycle analysis tool developed at SCK CEN (Belgian Nuclear Research Centre) to monitor the flow of nuclear material between facilities (Sect. 2.1), with a MOX equivalence code package. This package automatically governs the supply and demand of $\mathrm{Pu}$ isotopes required to obtain MOX equivalence, i.e. an energy equivalence principle which results in the in-core fuel management characteristics (cycle length, feed size, etc.) of a nuclear reactor remaining unchanged when replacing UOX fuel assemblies by MOX. The MOX assembly is totally characterised by its $\mathrm{Pu}$ quantity and a six-dimensional normalised vector defined by the isotopes ${ }^{238} \mathrm{Pu},{ }^{239} \mathrm{Pu},{ }^{240} \mathrm{Pu},{ }^{241} \mathrm{Pu},{ }^{242} \mathrm{Pu}$ and ${ }^{241} \mathrm{Am}$.

The MOX equivalence code package can determine the reactivity evolution for a given $\mathrm{Pu}$ vector and various $\mathrm{Pu}$ contents by means of a multidimensional interpolation on a directive grid of pre-calculated data tables generated by the reactor physics code WIMS10 [2], covering the physically accessible $\mathrm{Pu}$ vector space (Sect. 2.2). Subsequently, an on-line calculation of the $\mathrm{Pu}$ content requirements in MOX fuel fabrication is performed for a given fuel cycle scenario using the so-called Linear Reactivity Model (Sect. 2.3.1). For the purpose of demonstration, an assessment will be made for the evolution of the $\mathrm{Pu}$ vector in a realistic inventory of irradiated UOX fuel assemblies, assuming FIFO (First In, First Out) and LIFO (Last In, First Out) reprocessing strategies, and thereby defining the dimensional requirements of the interim fuel storage building (Sect. 3).

\section{Tools and methods}

In this section an overview is given of the tools and methods used to extend the fuel cycle analysis tool ANICCA with a MOX equivalence Python package. A description of ANICCA is provided to highlight the main capabilities of the code. Next, the methodology is detailed on how the required $\mathrm{Pu}$ fraction is calculated to achieve energy equivalence in MOX fuel at core reload by means of the proposed directive $\mathrm{Pu}$ vector grid and the application of the Linear Reactivity Model (LRM).

\subsection{Advanced Nuclear Inventory Cycle Code: ANICCA}

ANICCA [1] (a recursive acronym for Advanced Nuclear Inventory Cycle Code: ANICCA) is a fuel cycle analysis tool developed at SCK CEN to monitor the flow of nuclear material between facilities. It is a flexible and modular code written in the Python programming language that allows easily setting up, modifying and comparing different fuel cycle strategies. The application domain of this tool encompasses mid- and long-term cycle calculations for nuclear power plant fleet management, waste repository dimensioning, spent fuel reprocessing strategies, etc.

In this work version 1.2 of ANICCA has been used which requires a Python 3.5 compatible runtime environment. The nuclide data needed for the simulation of fuel cycle scenarios, such as isotope masses and different decay modes with their associated half-life, daughter products, yields, etc., are obtained from the JEFF-3.1/-3.1.1 radioactive decay data and fission yields sub-libraries [3] that are adapted to the internationally adopted ENDF-6 (Evaluated Nuclear Data File) format. The in-core irradiation of nuclear fuel assemblies can be simulated by means of pre-built libraries containing information about the averaged flux, effective full-power days of irradiation and averaged isotopic cross-sections and fission yields for a select number of burnup steps [1]. These libraries are generated by a post-processing of ALEPH2 [4] calculation results, an in-house SCK CEN Monte Carlo depletion code.

The specification of a fuel cycle scenario is done by means of a structured input file divided into four sections:

- scenario: set-up of general parameters such as time steps, nuclear data libraries, etc.;

- components: set-up in each participating facility of the cyclical or on-demand processes that need to occur at a given time requiring certain material packages to be received or sent away;

- connections: set-up of the material flows in the fuel cycle;

- viewers: set-up of observables such as mass balances, isotopic compositions, decay heat, radiotoxicity, etc. that need to be monitored at every time step.

To keep the code easily extendible, the core framework has been made small, generic and flexible, while allowing developers to add functionality using Python packages that are dynamically loaded during runtime. This important feature is used to extend ANICCA with the MOX equivalence Python code package which is detailed in Section 2.4.

\subsection{Directive $\mathrm{Pu}$ vector grid generation}

When considering a realistic inventory of spent UOX fuel assemblies resulting from decades of nuclear power plant operation, it becomes apparent that there is a rather large dispersion of the $\mathrm{Pu}$ vector. This diversity is the result of numerous aspects, such as the evolution of the in-core fuel management over time, the phase-in and phase-out of different reactor types and fuel designs, improvements of the fuel products resulting in higher discharge burnups, unforeseen events, etc. On a physical level the dispersion of the $\mathrm{Pu}$ vector isotopes is mainly due to the following processes:

- fuel assemblies with different burnups and enrichments;

- radioactive decay due to the cooling time of the spent fuel assembly between the last irradiation and reprocessing; 
- radioactive decay due to the delay between reprocessing and loading of the fuel in the core.

To accommodate for the dispersion, a multidimensional reactivity grid is considered for all realistically achievable $\mathrm{Pu}$ vectors, covering discharge burnups between 0 and $64 \mathrm{GWd} / \mathrm{tU}$ and $\mathrm{Pu}$ fractions of $6,8,10$ and $12 \%$ in the MOX assembly. Several options are possible to construct such a grid in a 6 dimensional space (6 independent isotopes in the $\mathrm{Pu}$ vector minus one normalisation constraint). One possible approach is to vary each $\mathrm{Pu}$ isotope parameter independently. However, when each parameter is varied over for example 5 discrete points to cover the dispersion, a total of already $5^{5}=3125$ calculations must be performed. This requires a high computation time and, above all, many calculated grid points are non-physical (i.e. they are never obtained in realistic $\mathrm{Pu}$ vectors). In order to exclude non-physical grid points, a directive grid generation is preferred. The variations of the parameters are all linked through the decay process (and to a lesser degree due to the variation of burnup and enrichment). Therefore, the grid is generated from a physical point of view, following more or less the variations due to the physical processes.

In practice, the directive $\mathrm{Pu}$ vector grid is generated by means of empirical correlations which provide the relative abundance of several isotopes for UOX fuel assemblies as a function of burnup at the moment of the core discharge and initial ${ }^{235} \mathrm{U}$ enrichment. These correlations were developed outside the scope of ANICCA in the framework of safety studies of a long-term storage installation by the Belgian National Agency for Radioactive Waste and enriched Fissile Material, NIRAS/ONDRAF [5]. They entail a series of empirically fitted polynomial and exponential functions for which the production of the nuclides within the fuel pellets and structural parts was calculated using the ORIGEN2 code (for the active zone) with, for the actinides, burnup dependent cross-section libraries established with the assembly code CASMO. Different correlations were established for typical fuel assembly geometries $(14 \times 148 \mathrm{ft}$., $15 \times 1512 \mathrm{ft}$., $17 \times 17$ $12 \mathrm{ft}$., and $17 \times 1714 \mathrm{ft}$.) with varying fuel enrichments, mostly fuelled with UOX fuel issued from enriched natural uranium (ENU), but also enriched reprocessed uranium (ERU) and MOX fuels were used. The list of covered isotopes can be consulted in Table 18 of [5] and can be summarised as:

$$
\begin{aligned}
& -{ }^{232} \mathrm{U},{ }^{233} \mathrm{U},{ }^{234} \mathrm{U},{ }^{235} \mathrm{U},{ }^{236} \mathrm{U},{ }^{238} \mathrm{U} ; \\
& -{ }^{236} \mathrm{Pu},{ }^{238} \mathrm{Pu},{ }^{239} \mathrm{Pu},{ }^{240} \mathrm{Pu},{ }^{241} \mathrm{Pu},{ }^{242} \mathrm{Pu},{ }^{244} \mathrm{Pu} ; \\
& -{ }^{241} \mathrm{Am},{ }^{242 m} \mathrm{Am},{ }^{243} \mathrm{Am} ; \\
& -{ }^{242} \mathrm{Cm},{ }^{243} \mathrm{Cm},{ }^{244} \mathrm{Cm},{ }^{245} \mathrm{Cm},{ }^{246} \mathrm{Cm},{ }^{247} \mathrm{Cm},{ }^{248} \mathrm{Cm} ; \\
& \text { - fission products with low atomic mass number. }
\end{aligned}
$$

\subsubsection{Reference Pu vector}

The generation of the grid starts from reference $\mathrm{Pu}$ vectors calculated for the conditions in Table 1, which are representative of a typical PWR in-core fuel management, and from where perturbations will be calculated in order to
Table 1. Reference $\mathrm{Pu}$ vector parameters.

\begin{tabular}{ll} 
UOX enrichment & $4.3 \%{ }^{235} \mathrm{U}$ \\
Burnup range & $1-80 \mathrm{GWd} / \mathrm{tU}$ \\
Cooling time of fuel assembly & 21 years \\
Core reload delay after reprocessing & 1 year \\
\hline
\end{tabular}

cover the $\mathrm{Pu}$ vector dispersion. Experience with realistic $\mathrm{Pu}$ vectors shows that ${ }^{239} \mathrm{Pu}$ and ${ }^{240} \mathrm{Pu}$ are the most abundant isotopes, occupying a total of 70 to $100 \%$ of the $\mathrm{Pu}$ vector. Therefore, the main parameter variation of the grid is defined as the sum of the contributions of ${ }^{239} \mathrm{Pu}$ and ${ }^{240} \mathrm{Pu}$, from now on defined as the parameter $\alpha$. This parameter is also a good measure of assembly burnup as its value decreases monotonically during the irradiation process due to the relative increase of other isotopes in the (normalised) $\mathrm{Pu}$ vector. For each value of $\alpha$, a reference $\mathrm{Pu}$ vector is defined as a starting point for the grid construction. The reference vector is based on the empirical correlations previously discussed, where the variation of $\alpha$ (between 70 and 100\%) is obtained by varying the burnup of the spent fuel. The resulting $\mathrm{Pu}$ vectors are listed in Table 2.

\subsubsection{Grid generation algorithm}

The purpose of the grid generation algorithm is to generate normalised $\mathrm{Pu}$ vectors in the 6 dimensional grid with coordinates:

$$
\left({ }^{238} \mathrm{Pu},{ }^{239} \mathrm{Pu},{ }^{240} \mathrm{Pu},{ }^{241} \mathrm{Pu},{ }^{242} \mathrm{Pu},{ }^{241} \mathrm{Am}\right) .
$$

The starting point is the reference vector (Sect. 2.2.1), which depends on $\alpha$ and has coordinates given by:

$$
\begin{aligned}
\left({ }_{\text {ref }}^{238} \mathrm{Pu}(\alpha), \underset{\text { ref }}{239} \mathrm{Pu}(\alpha),{ }_{\text {ref }}^{240} \mathrm{Pu}(\alpha),\right. \\
\left.\quad{ }_{\text {ref }}^{241} \mathrm{Pu}(\alpha),{ }_{\text {ref }}^{242} \mathrm{Pu}(\alpha),{ }_{\text {ref }}^{241} \mathrm{Am}(\alpha)\right) .
\end{aligned}
$$

The first step consists of a discretisation in $\alpha$ :

$$
\alpha=\left(\alpha_{1}, \alpha_{2}, \ldots, \alpha_{n}\right),
$$

with $70 \%<\alpha<100 \%$. For each value $\alpha_{i}$, the reference $\mathrm{Pu}$ vector is obtained by linear interpolation of each isotope in Table 2. Next, a perturbation to ${ }^{239} \mathrm{Pu}$ and ${ }^{240} \mathrm{Pu}$ with respect to the reference vector is defined as:

$$
\begin{aligned}
& { }^{239} \mathrm{Pu}={ }_{\text {ref }}^{239} \mathrm{Pu}+\delta_{1}, \\
& { }^{240} \mathrm{Pu}={ }_{\text {ref }}^{240} \mathrm{Pu}-\delta_{1} .
\end{aligned}
$$

A perturbation $+\delta_{1}$ to ${ }^{239} \mathrm{Pu}$ must be compensated by $-\delta_{1}$ to ${ }^{240} \mathrm{Pu}$ in order to maintain the $\mathrm{Pu}$ vector normalisation. Next, a perturbation $+\delta_{2}$ to ${ }^{242} \mathrm{Pu}$ is done:

$$
{ }^{242} \mathrm{Pu}={ }_{\text {ref }}^{242} \mathrm{Pu}+\delta_{2} .
$$

By perturbing the amount of ${ }^{242} \mathrm{Pu}$, normalisation is lost and the reference vector must change accordingly. This implies a renormalisation of the reference vector over 
Table 2. Reference Pu vector for varying assembly discharge burnups.

\begin{tabular}{llllllll}
\hline $\begin{array}{l}\text { Burnup } \\
{[\mathrm{MWd} / \mathrm{tU}]}\end{array}$ & $\alpha \%]$ & ${ }^{238} \mathrm{Pu}$ & $\begin{array}{l}{ }^{239} \mathrm{Pu} \\
{[\%]}\end{array}$ & $\begin{array}{l}{ }^{240} \mathrm{Pu} \\
{[\%]}\end{array}$ & $\begin{array}{l}{ }^{241} \mathrm{Pu} \\
{[\%]}\end{array}$ & $\begin{array}{l}{ }^{242} \mathrm{Pu} \\
{[\%]}\end{array}$ & $\begin{array}{l}{ }^{241} \mathrm{Am} \\
{[\%]}\end{array}$ \\
\hline 1000 & 99.96 & 0.01 & 98.26 & 1.71 & 0.03 & 0.00 & 0.00 \\
5000 & 99.43 & 0.05 & 92.60 & 6.83 & 0.46 & 0.04 & 0.02 \\
10000 & 98.24 & 0.15 & 86.90 & 11.34 & 1.31 & 0.23 & 0.06 \\
15000 & 96.62 & 0.32 & 81.80 & 14.82 & 2.32 & 0.63 & 0.11 \\
20000 & 94.73 & 0.55 & 77.08 & 17.64 & 3.30 & 1.26 & 0.16 \\
25000 & 92.73 & 0.83 & 72.76 & 19.97 & 4.16 & 2.08 & 0.21 \\
30000 & 90.72 & 1.16 & 68.82 & 21.90 & 4.83 & 3.05 & 0.24 \\
35000 & 88.75 & 1.54 & 65.26 & 23.49 & 5.32 & 4.12 & 0.26 \\
40000 & 86.85 & 1.96 & 62.06 & 24.80 & 5.66 & 5.25 & 0.28 \\
45000 & 85.03 & 2.40 & 59.16 & 25.87 & 5.88 & 6.40 & 0.29 \\
50000 & 83.28 & 2.85 & 56.53 & 26.74 & 6.01 & 7.56 & 0.30 \\
55000 & 81.60 & 3.30 & 54.14 & 27.45 & 6.09 & 8.71 & 0.30 \\
60000 & 79.99 & 3.74 & 51.96 & 28.03 & 6.12 & 9.84 & 0.30 \\
80000 & 74.44 & 5.08 & 44.80 & 29.64 & 6.05 & 14.13 & 0.30 \\
\hline
\end{tabular}

the three remaining isotopes (the notation also includes $\left.{ }^{241} \mathrm{Am}\right)$ :

$$
{ }_{\operatorname{ref}}^{i} \mathrm{Pu}^{\prime}=\underset{\text { ref }}{i} \mathrm{Pu}-w_{i} \delta_{2},
$$

with $w_{i}={ }_{\text {ref }}^{i} \mathrm{Pu} /\left({ }_{\text {ref }}^{238} \mathrm{Pu}+{ }_{\text {ref }}^{241} \mathrm{Pu}+{ }_{\text {ref }}^{241} \mathrm{Am}\right)$ the fraction of the remaining isotopes. The next step is to consider the simultaneous variation of ${ }^{241} \mathrm{Pu}$ and ${ }^{241} \mathrm{Am}$. In order to keep the normalisation, ${ }^{238} \mathrm{Pu}$ must be varied accordingly. As a result, this simultaneous variation can be treated as a single variation $+\delta_{3}$ in ${ }^{238} \mathrm{Pu}$ :

$$
{ }^{238} \mathrm{Pu}={ }_{\text {ref }}^{238} \mathrm{Pu}+\delta_{3} .
$$

The remaining isotopes ${ }^{241} \mathrm{Pu}$ and ${ }^{241} \mathrm{Am}$ must be renormalised over the remaining part, i.e. $-\delta_{3}$ :

$$
{ }_{\text {ref }}^{j} \mathrm{Pu}^{\prime \prime}={ }_{\text {ref }}^{j} \mathrm{Pu}^{\prime}-w_{j} \delta_{3},
$$

with $w_{j}={ }_{\text {ref }}^{j} \mathrm{Pu}^{\prime} /\left({ }_{\text {ref }}^{241} \mathrm{Pu}^{\prime}+{ }_{\text {ref }}^{241} \mathrm{Am}^{\prime}\right)$ the fraction of the remaining isotopes. In a last step, the decay of ${ }^{241} \mathrm{Pu}$ to ${ }^{241} \mathrm{Am}$ is emulated by swapping an amount $\delta_{4}$ between ${ }^{241} \mathrm{Pu}$ and ${ }^{241} \mathrm{Am}$ :

$$
\begin{aligned}
& { }^{241} \mathrm{Pu}={ }_{\text {ref }}^{241} \mathrm{Pu}^{\prime \prime}+\delta_{4}, \\
& { }^{241} \mathrm{Am}={ }_{\text {ref }}^{241} \mathrm{Am}^{\prime \prime}-\delta_{4} .
\end{aligned}
$$

In practice, the swapping between ${ }^{241} \mathrm{Am}$ and ${ }^{241} \mathrm{Pu}$ is done by covering all the possible combinations. A fixed step size (e.g. $2 \%$ ) is used when incrementing ${ }^{241} \mathrm{Pu}$ up to its maximal value, while compensating the ${ }^{241} \mathrm{Am}$ accordingly.

\subsubsection{Determination of the grid boundaries}

A proper execution of the grid generation algorithm requires the variation of the parameters $\delta_{1}, \delta_{2}, \delta_{3}$ and $\delta_{4}$, for a fixed value of $\alpha_{i}$. These variations with respect to the reference vector must cover the entire isotopic vector space at a sufficient resolution. Therefore, the boundaries of the grid need to be determined:

$$
\begin{aligned}
& \delta_{1, \text { min }} \leq \delta_{1} \leq \delta_{1, \text { max }}, \\
& \delta_{2, \text { min }} \leq \delta_{2} \leq \delta_{2, \text { max }}, \\
& \delta_{3, \text { min }} \leq \delta_{3} \leq \delta_{3, \text { max }} .
\end{aligned}
$$

The variation of each $\delta_{i}$ is performed by a fixed step size $\delta_{i}^{\text {step }}$, which defines the density of the grid. Boundary values for the ${ }^{241} \mathrm{Pu} /{ }^{241} \mathrm{Am}$ variation $\delta_{4}$ are not needed as the mutual swapping covers all the combinations.

In order to determine the grid boundaries, the $\mathrm{Pu}$ vector of various fuel assemblies from the Belgian PWR fleet have been analysed for a series of cooling and waiting times, enrichments and fuel assembly burnups. Available complementary data from other power plants have been added as well. For each known $\mathrm{Pu}$ vector, a reversed approach with respect to Section 2.2.2 is applied. The reference vector is determined by linear interpolation at the corresponding $\alpha$ value in Table 2 . The following deviations are calculated:

$$
\begin{aligned}
& \Delta^{239} \mathrm{Pu}={ }^{239} \mathrm{Pu}-{ }_{\text {ref }}^{239} \mathrm{Pu}, \\
& \Delta^{240} \mathrm{Pu}={ }^{240} \mathrm{Pu}-{ }_{\text {ref }}^{240} \mathrm{Pu} .
\end{aligned}
$$

Because $\alpha$ is constant: $\Delta^{239} \mathrm{Pu}=-\Delta^{240} \mathrm{Pu}$. Next, the deviation $\Delta^{242} \mathrm{Pu}$ is calculated:

$$
\Delta^{242} \mathrm{Pu}={ }^{242} \mathrm{Pu}-{ }_{\text {ref }}^{242} \mathrm{Pu} .
$$

Due to the change of $\Delta^{242} \mathrm{Pu}$, the reference vector must be renormalised over the remaining isotopes:

$$
{ }_{\text {ref }}^{i} \mathrm{Pu}^{\prime}=\underset{\text { ref }}{i} \mathrm{Pu}-w_{i} \Delta^{242} \mathrm{Pu},
$$




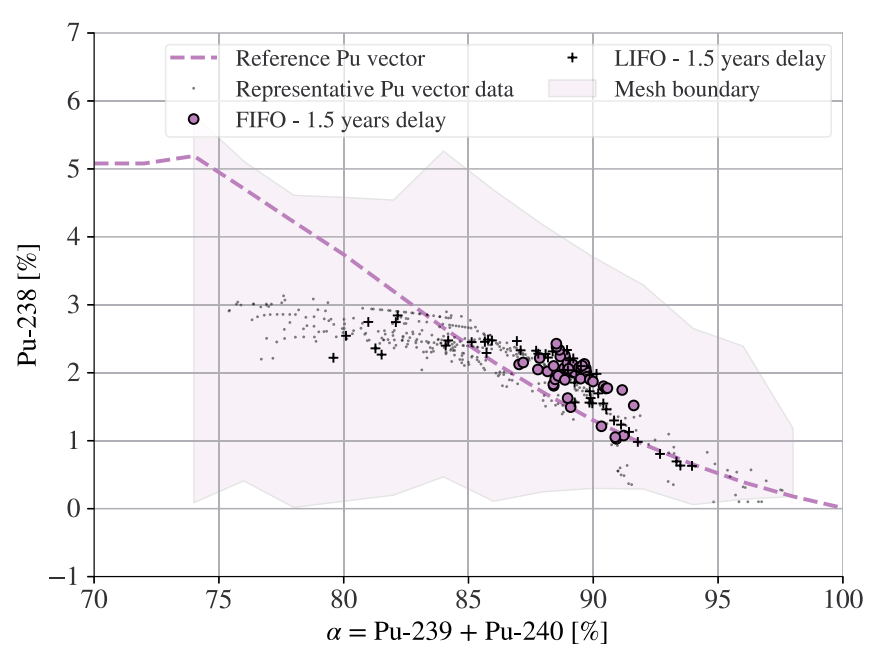

(a) ${ }^{238} \mathrm{Pu}$

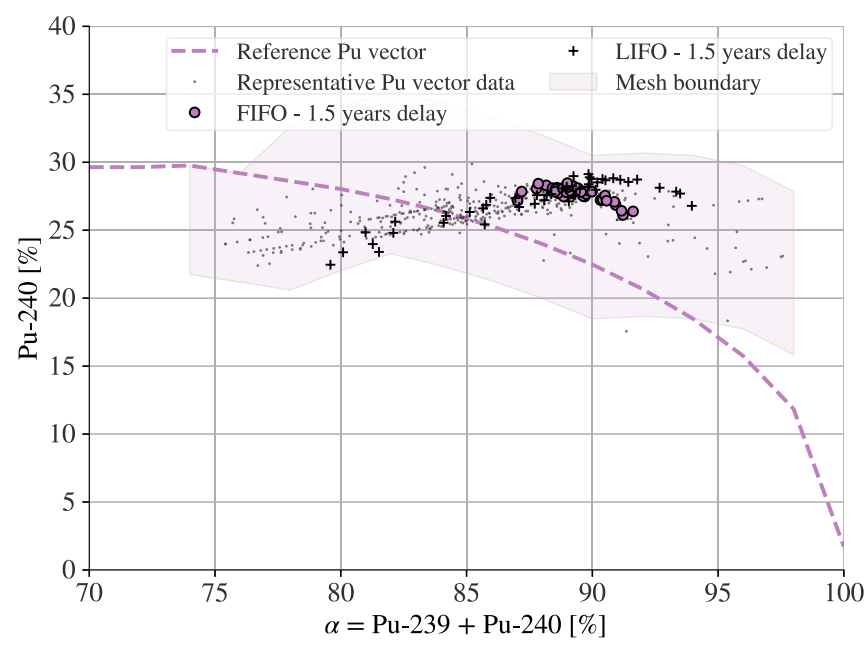

(c) ${ }^{240} \mathrm{Pu}$

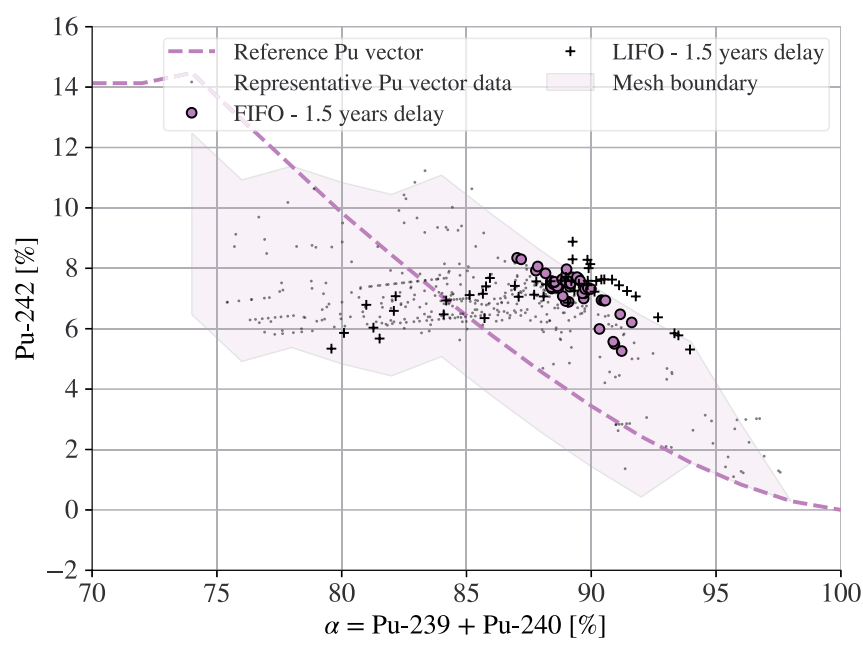

(e) ${ }^{242} \mathrm{Pu}$

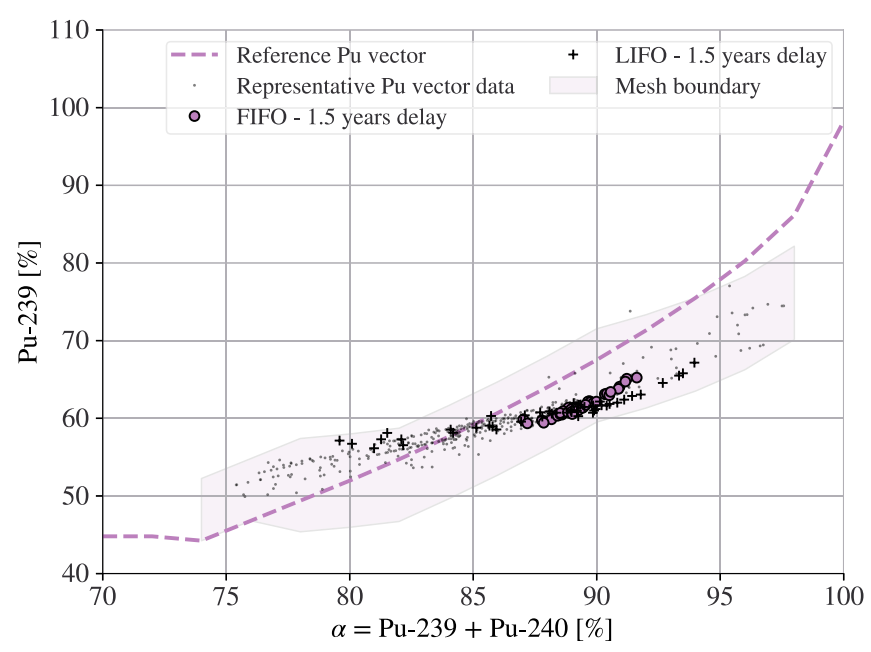

(b) ${ }^{239} \mathrm{Pu}$

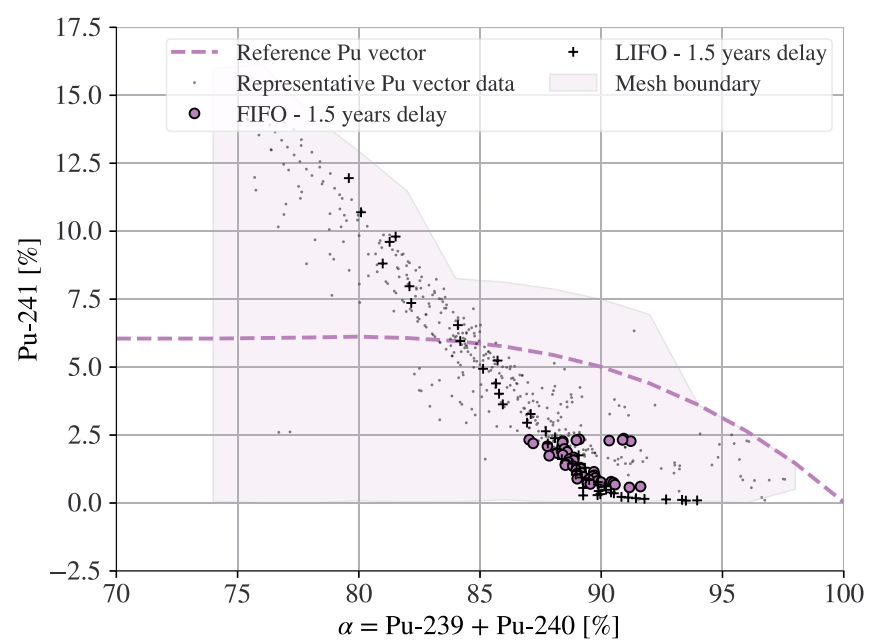

(d) ${ }^{241} \mathrm{Pu}$

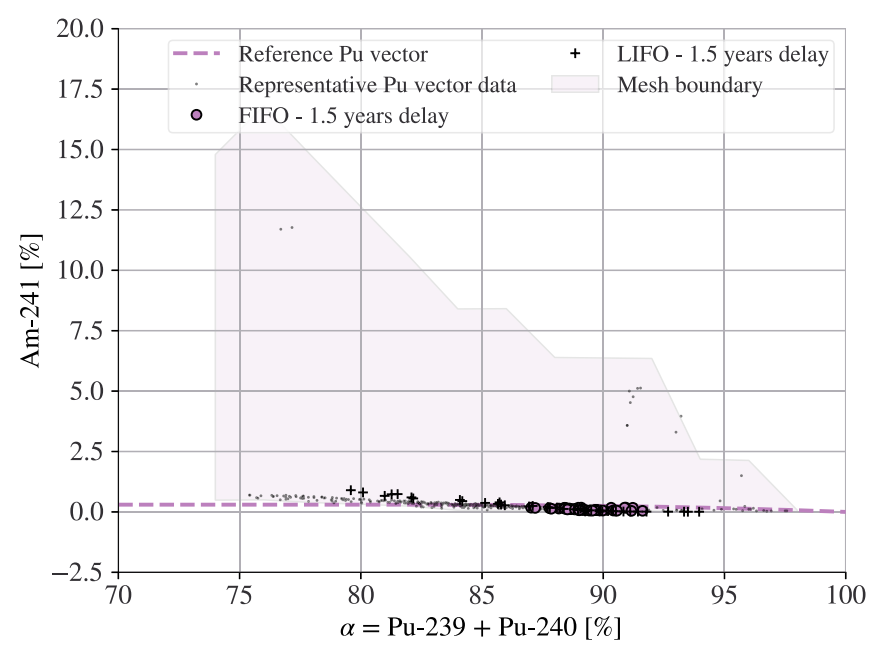

(f) ${ }^{241} \mathrm{Am}$

Fig. 1. Directive $\mathrm{Pu}$ vector grid. The reference $\mathrm{Pu}$ vectors are estimated under the conditions listed in Table $1 . \mathrm{The}$ realistic $\mathrm{Pu}$ vector data is used to outline the grid boundaries of the directive Pu vector grid. The FIFO and LIFO scenarios with 1.5 years of delay between reprocessing and core reload are further discussed in Section 3. 
Table 3. Grid boundary values determined from the flyspecks. The number of valid (i.e. all components positive) $\mathrm{Pu}$ vectors per value of $\alpha$ is given in the last column.

\begin{tabular}{llllllll}
\hline$\alpha$ & $\begin{array}{l}\Delta^{239} \mathrm{Pu} \\
\min \end{array}$ & $\begin{array}{l}\Delta^{239} \mathrm{Pu} \\
\max \end{array}$ & $\begin{array}{l}\Delta^{242} \mathrm{Pu} \\
\min \end{array}$ & $\begin{array}{l}\Delta^{242} \mathrm{Pu} \\
\max \end{array}$ & $\begin{array}{l}\Delta^{238} \mathrm{Pu} \\
\min \end{array}$ & $\begin{array}{l}\Delta^{238} \mathrm{Pu} \\
\max \end{array}$ & $\begin{array}{l}\text { \# valid } \\
\text { grid points }\end{array}$ \\
\hline 74 & 0 & 8 & -8 & -2 & -6 & -3 & 415 \\
76 & 0 & 8 & -8 & -2 & -6 & -3 & 390 \\
78 & -4 & 8 & -6 & 0 & -5 & -2 & 469 \\
80 & -6 & 6 & -5 & 1 & -4 & -1 & 413 \\
82 & -8 & 4 & -4 & 2 & -3 & 0 & 364 \\
84 & -8 & 4 & -2 & 4 & -1 & 2 & 252 \\
86 & -8 & 4 & -2 & 4 & -1 & 2 & 231 \\
88 & -8 & 4 & -2 & 4 & -1 & 2 & 210 \\
90 & -8 & 4 & -2 & 4 & -1 & 2 & 168 \\
92 & -10 & 2 & -2 & 4 & -1 & 2 & 126 \\
94 & -12 & 0 & -2 & 4 & -1 & 2 & 63 \\
96 & -14 & -2 & -2 & 4 & -1 & 2 & 42 \\
98 & -16 & -4 & -2 & 4 & -1 & 2 & 14 \\
\hline
\end{tabular}

with $w_{i}={ }_{\text {ref }}^{i} \mathrm{Pu} /\left({ }_{\text {ref }}^{238} \mathrm{Pu}+{ }_{\text {ref }}^{241} \mathrm{Pu}+{ }_{\text {ref }}^{241} \mathrm{Am}\right)$ the fraction of the remaining isotopes. Next, the deviation $\Delta^{238} \mathrm{Pu}$ is calculated:

$$
\Delta^{238} \mathrm{Pu}={ }^{238} \mathrm{Pu}-{ }_{\text {ref }}^{238} \mathrm{Pu}^{\prime} .
$$

Further steps regarding the deviation and renormalisation of ${ }^{241} \mathrm{Pu}$ and ${ }^{241} \mathrm{Am}$ are not needed because the mutual swapping covers their contributions. This process is repeated for each known isotopic vector and results in a flyspeck of $\Delta^{239} \mathrm{Pu}, \Delta{ }^{242} \mathrm{Pu}$ and $\Delta^{238} \mathrm{Pu}$ as a function of $\alpha$.

The representative $\mathrm{Pu}$ vectors plotted in Figure 1 are used to set the boundaries of the so-called directive grid of physically accessible $\mathrm{Pu}$ vectors. This directive grid is constructed as a collection of well-distributed, realistic $\mathrm{Pu}$ vectors at $2 \%$-spaced intervals for $74 \%<\alpha<100 \%$, with the grid step sizes $\delta_{i}^{\text {step }}$ set as follows:

$$
\begin{aligned}
& -\delta_{1}: 2 \%\left({ }^{239} \mathrm{Pu} /{ }^{240} \mathrm{Pu}\right) \\
& -\delta_{2}: 2 \%\left({ }^{242} \mathrm{Pu}\right) \\
& -\delta_{3}: 1 \%\left({ }^{238} \mathrm{Pu}\right) ; \\
& -\delta_{4}: 2 \%\left({ }^{241} \mathrm{Pu} /{ }^{241} \mathrm{Am}\right) .
\end{aligned}
$$

The grid boundaries $\delta_{i, \min / \max }$ determined from the flyspecks are shown in Table 3 .

\subsubsection{MOX data table generation on grid points}

For every unique point identified in the directive $\mathrm{Pu}$ vector grid, a series of calculations of the infinite multiplication factor $k_{\infty}$ are done as a function of assembly burnup. These calculations are repeated for the discrete $\mathrm{Pu}$ fractions of $6,8,10$ and $12 \%$ in the MOX assembly, covering the realistically achievable range of $\mathrm{Pu}$ content in industrial MOX fuel fabrication. Such a set of four evolutions of the assembly reactivity will be called a MOX data table during the remainder of the discussion. Certain grid points within the range covered by Table 3 will result in $\mathrm{Pu}$ vectors with one or more negative components. Such nonphysical $\mathrm{Pu}$ vectors are excluded from MOX data table

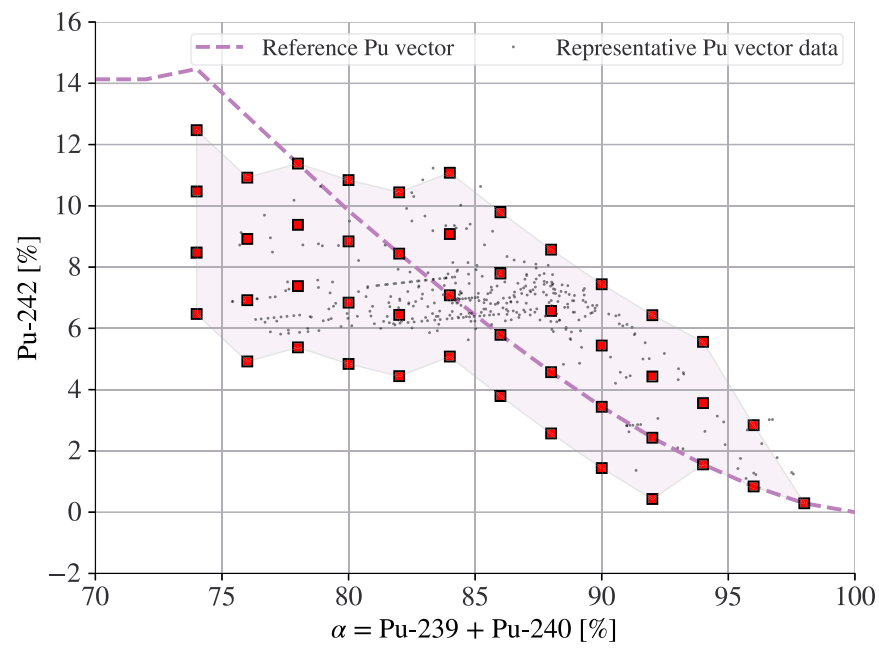

Fig. 2. Construction of the directive $\mathrm{Pu}$ vector grid (red squares) for ${ }^{242} \mathrm{Pu}$ that covers the physically accessible $\mathrm{Pu}$ vector space.

generation. The number of valid $\mathrm{Pu}$ vectors per value of $\alpha$ is given in the last column of Table 3. An example of (valid) grid points is given for ${ }^{242} \mathrm{Pu}$ in Figure 2.

The MOX data tables are generated using the deterministic reactor physics code WIMS10 [2] by means of lattice cell calculations and solving the multi-group neutron transport equations using a characteristics method that integrates the transport equation over characteristic directions. These calculations are done for a specific MOX fuel assembly geometry at typical reactor operating conditions. In total about 3000 WIMS10 calculations are performed to cover the entire grid with MOX data tables.

\subsection{MOX energy equivalence}

In the current industrial scheme, MOX fuel is recycled in LWRs, where the fraction of MOX assemblies loaded in the core is typically limited to 30 to $40 \%$ of the fresh feed, balanced by an enriched UOX fuel complement. When 
replacing a UOX assembly by MOX, the operator prefers to keep the cycle length (amount of produced energy) and feed size (number of fresh assemblies) unchanged. The design of the MOX fuel assembly and the loading patterns are such that the same burnup can be reached in the MOX fuel assemblies as in the UOX fuel assemblies, in particular with respect to the rod internal pressure. This is the basis of the energy equivalence principle. MOX equivalence is defined by tuning the $\mathrm{Pu}$ content in the MOX fuel, considering the specific $\mathrm{Pu}$ isotopic vector at the time of the core reload to obtain a crossing of the reactivity curves of UOX and MOX at the end-of-cycle core average burnup. The required $\mathrm{Pu}$ content depends on the quality of the $\mathrm{Pu}$ vector.

\subsubsection{Linear reactivity model}

The Linear Reactivity Model (LRM) is developed to analytically predict the reactivity evolution of UOX and MOX fuels. It is a bi-linear equation providing the reactivity $(\rho)$ as a function of burnup $(B U)$ and ${ }^{235} \mathrm{U}$ enrichment or $\mathrm{Pu}$ fraction $(\epsilon)$, in case of UOX or MOX respectively, and four calibrated parameters $\rho_{0}, B E, B B$ and $B E B$. These model parameters depend on reactor and fuel characteristics and can be obtained by calibrating them using explicit WIMS10 reactivity calculation output. For the UOX fuel, the LRM calibration is performed directly on the WIMS10 output. In case of the MOX fuel, this calibration is done on a MOX data table obtained from the directive grid developed in Section 2.2 matching the $\mathrm{Pu}$ vector at core reload. The latter is done by means of a multidimensional linear fit scheme to search for the two nearest points in the grid for each isotope in the $\mathrm{Pu}$ vector. In case a $\mathrm{Pu}$ vector component lies outside the grid boundary, a linear extrapolation is performed based on the two nearest points.

In an equilibrium cycle, the core average burnup is completely defined by the fraction of the core which is replaced at each cycle and the cycle length. The UOX core average reactivity at that burnup is the fitting parameter used to force the LRM to cope with reference full core calculations. The same reactivity is assumed to apply to mixed UOX-MOX cores.

The UOX reactivity at the end-of-cycle core average burnup is calculated using the UOX LRM equation, i.e. (1) in Figure 3:

$$
\rho_{U}=\rho_{0}+B E \cdot \epsilon_{U}+\left(B E B \cdot \epsilon_{U}+B B\right) \cdot B U_{E O C} .
$$

The MOX LRM linear equation is solved for the $\mathrm{Pu}$ fraction as follows:

$$
\epsilon_{P u}=\frac{\rho_{U}-\rho_{0}^{\prime}-B B^{\prime} \cdot B U_{E O C}}{B E^{\prime}+B E B^{\prime} \cdot B U_{E O C}} .
$$

Note that a specific notation is used to clearly distinguish between UOX (without prime) and MOX fuel (with prime). Requesting equal reactivity of the UOX and MOX curves at the end-of-cycle average core burnup, i.e. (2) in Figure 3, allows to calculate the required $\mathrm{Pu}$ fraction from the LRM analytical equations for any given UOX enrichment and $\mathrm{Pu}$ vector, i.e. (3) in Figure 3.

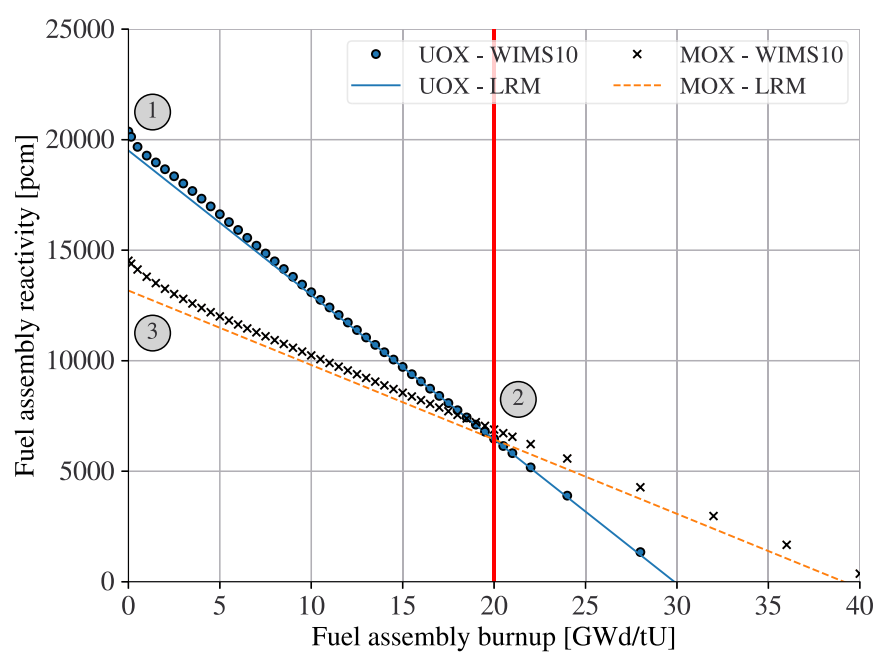

Fig. 3. Calculation of the required $\mathrm{Pu}$ content using the Linear Reactivity Model for an equivalence request at an end-of-cycle burnup of $20 \mathrm{GWd} / \mathrm{tU}$.

\subsubsection{LRM accuracy}

A flyspeck benchmark is performed on the ensemble of MOX data tables calculated to constitute the $\mathrm{Pu}$ vector grid (Sect. 2.2.4). This demonstrates the effectiveness of the LRM, without the secondary effect of the $\mathrm{Pu}$ vector and burnup interpolation between MOX data tables. For the considered $\mathrm{Pu}$ fractions $(6,8,10$ and $12 \%)$, histograms were constructed in Figure 4 to provide the distribution of the reactivity discrepancy between the exact WIMS10 calculations and the LRM estimations. The burnup range for LRM calibration is typically limited to a range of 14 to $55 \mathrm{GWd} / \mathrm{tU}$ to exclude high discrepancies resulting from a strong non-linear behaviour of the reactivity evolution in high- ${ }^{241} \mathrm{Am} \mathrm{Pu}$ vectors at the beginning of irradiation. This reduced burnup range is justified as the end-of-cycle core average burnup for which a crossing of the reactivity curves of UOX and MOX is requested typically will be within this range.

For the extremal $\mathrm{Pu}$ fractions of 6 and 12\%, the LRM shows a dispersion up to $\sim 1000 \mathrm{pcm}$ over the entire grid domain, but corresponds on average rather well to the WIMS10 calculations. The reactivity discrepancies at intermediate $\mathrm{Pu}$ fractions of 8 and $10 \%$ are less dispersed $(\sim 500 \mathrm{pcm})$, but LRM results are on average underestimated by $\sim 500 \mathrm{pcm}$.

A proposed solution to reduce biases is adding a quadratic term to the LRM equation. Additionally, performing a direct linear interpolation of the MOX fuel reactivity at each calculated burnup step using neighbouring (in terms of $\mathrm{Pu}$ vector) MOX data tables (Sect. 2.2.4) could reduce the dispersion. However, a sufficiently high MOX data table grid density would be required in the latter case to limit discrepancies caused by linear interpolation. Both approaches have shown promising results which are not discussed within the scope of this work.

The currently achieved model accuracy is considered sufficient for practical fuel cycle scenario studies and will e.g. amount to only a few tens of ppm in critical boron 


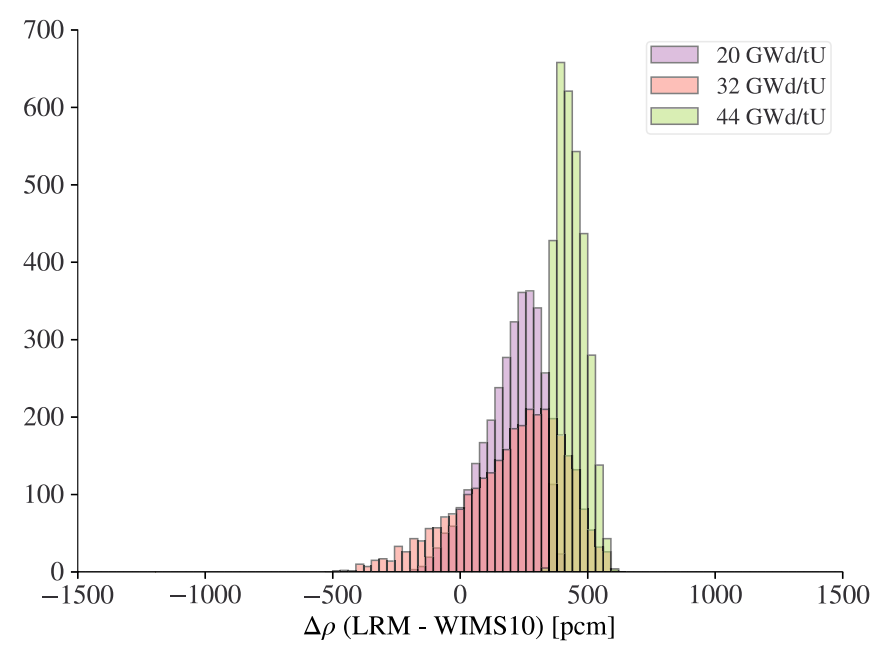

(a) $6 \% \mathrm{Pu}$ content

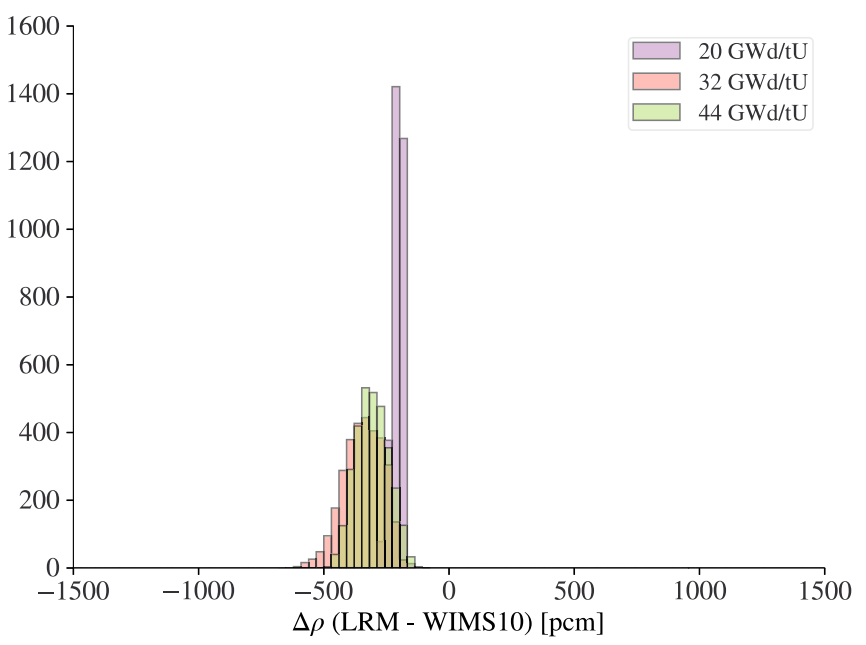

(c) $10 \% \mathrm{Pu}$ content

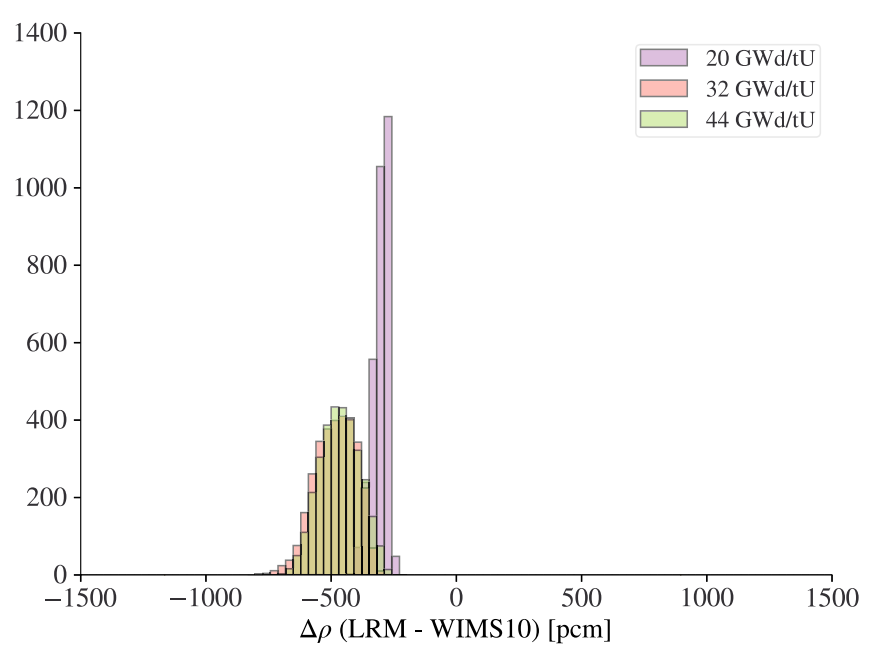

(b) $8 \% \mathrm{Pu}$ content

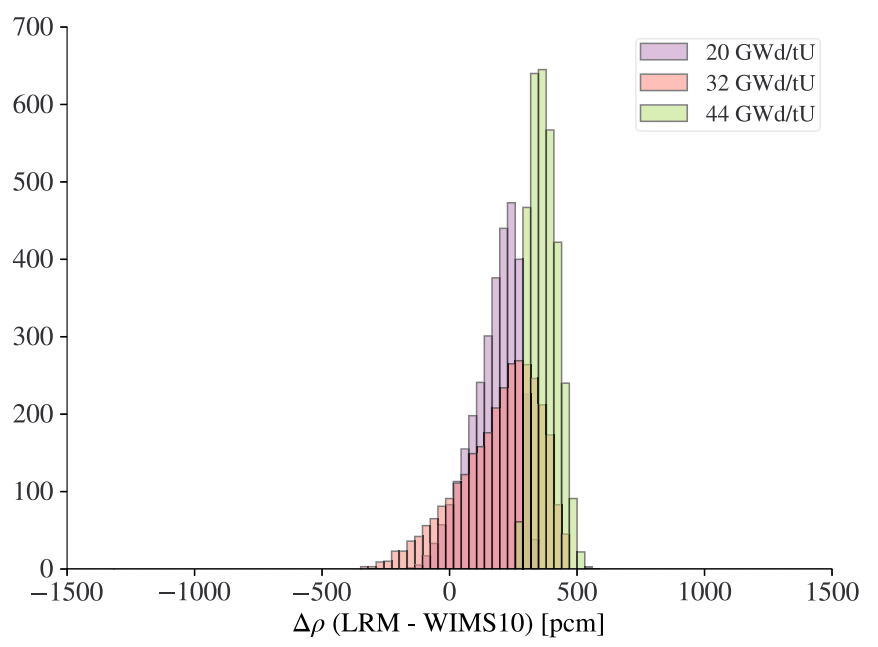

(d) $12 \% \mathrm{Pu}$ content

Fig. 4. Distribution of reactivity discrepancy (LRM - WIMS10) for the ensemble of generated MOX data tables.

concentration discrepancy, especially when the typical MOX fraction in the reactor core is restricted to about 30 to $40 \%$. Systematic biases can be absorbed by tuning the calibration parameter $\rho_{0}$ in the UOX LRM equation (Sect. 2.3.1) on an explicit reference core calculation for which the required $\mathrm{Pu}$ content is explicitly calculated.

\subsubsection{Overview of equivalence models}

Equivalence models are used to calculate the fresh fuel mass requirements as a function of the isotopic vector of the source material. They are mainly used for fuel types other than enriched natural uranium-based fuel (ENU), such as e.g. MOX fuel, Th- ${ }^{233} \mathrm{U}$ fuel, or reprocessed uranium (repU) fuel because of their variability in isotopic vector, and hence, reactivity content. Modern equivalence models can be broadly divided into the following categories [6]:
- perturbative equivalence model: the premise of this model is that a large variety of isotopic mixtures yield nearly the same critical mass as a reference fuel, if their weight percentages multiplied by specific isotopic importance factors lead to the same total importance factor as for the reference fuel. These importance factors are often denoted as the "Baker and Ross" [7] critical-mass-worth weight factors and are defined for each $\mathrm{Pu}$ vector component (relative to the worth of ${ }^{239} \mathrm{Pu}$ ) as:

$$
w_{i}=\frac{w_{i}^{\rho}-w_{8}^{\rho}}{w_{9}^{\rho}-w_{8}^{\rho}} \simeq \frac{\left(\nu \sigma_{f}-\sigma_{a}\right)_{i}-\left(\nu \sigma_{f}-\sigma_{a}\right)_{8}}{\left(\nu \sigma_{f}-\sigma_{a}\right)_{9}-\left(\nu \sigma_{f}-\sigma_{a}\right)_{8}},
$$

with $i, 8,9$ denoting respectively a $\mathrm{Pu}$ vector component ${ }^{i} \mathrm{Pu},{ }^{238} \mathrm{U}$ and ${ }^{239} \mathrm{Pu}$. These importance factors are calculated once for the reference fuel using a lattice/core transport code and subsequently applied to other fuel compositions. This method is easy to 
implement and its analytical form allows to perform uncertainty propagation. The main drawback of this method is that it is only reliable for small modifications with respect to the reference fuel as it is based on perturbation theory;

- direct transport/depletion computation: this method calculates iteratively the fissile content using a transport and depletion code, until reaching a satisfying end-of-cycle core reactivity. Although this method is robust and accurate it also is computationally very intensive;

- tabulated model: this method uses pre-calculated data on which several regression and parametrisation techniques can be applied. Such methods are reliable, fast, and easy to interpret but cannot perform uncertainty propagation, as they are not parametrised with nuclear data. The LRM described in Section 2.3.1 is an application of a tabulated model;

- data-driven equivalence model: this method is based on statistical estimators, such as e.g. artificial neural networks. The idea behind this approach is to construct a surrogate model that e.g. provides the required $\mathrm{Pu}$ content to obtain zero end-of-cycle reactivity and is calibrated on $\mathrm{Pu}$ vectors randomly sampled from reference calculations. Although similar to tabulated models, an important advantage of advanced neural network surrogate-based models is that they enable the propagation of cross-section uncertainties.

The directive $\mathrm{Pu}$ vector grid approach coupled to a LRM is independent of the in-core fuel management (feed size, cycle length, etc.) of the considered fuel cycle scenario. This makes the methodology proposed in this work versatile for performing fuel cycle scenario analysis, without e.g. the need to redetermine importance factors upfront whenever the in-core fuel management is changed.

\subsection{MOX equivalence Python code package}

The MOX equivalence code package is a collection of Python modules that are dynamically loaded during ANICCA runtime, encompassing:

- a stockpile module which extracts material packages from a predetermined inventory following a user-defined sequence and combines them into a homogenised mixture (subclass of the ANICCA Conversion process);

- a LRM fitting module which generates a bestmatching MOX data table from the directive $\mathrm{Pu}$ vector grid data and calibrates the LRM parameters accordingly;

- a MOX equivalence module which calculates the required $\mathrm{Pu}$ content in $\mathrm{MOX}$ fuel for a given $\mathrm{Pu}$ vector to obtain energy equivalence (subclass of the ANICCA Combine process);

- a series of helper-scripts for generating the directive $\mathrm{Pu}$ vector grid and post-processing of results.

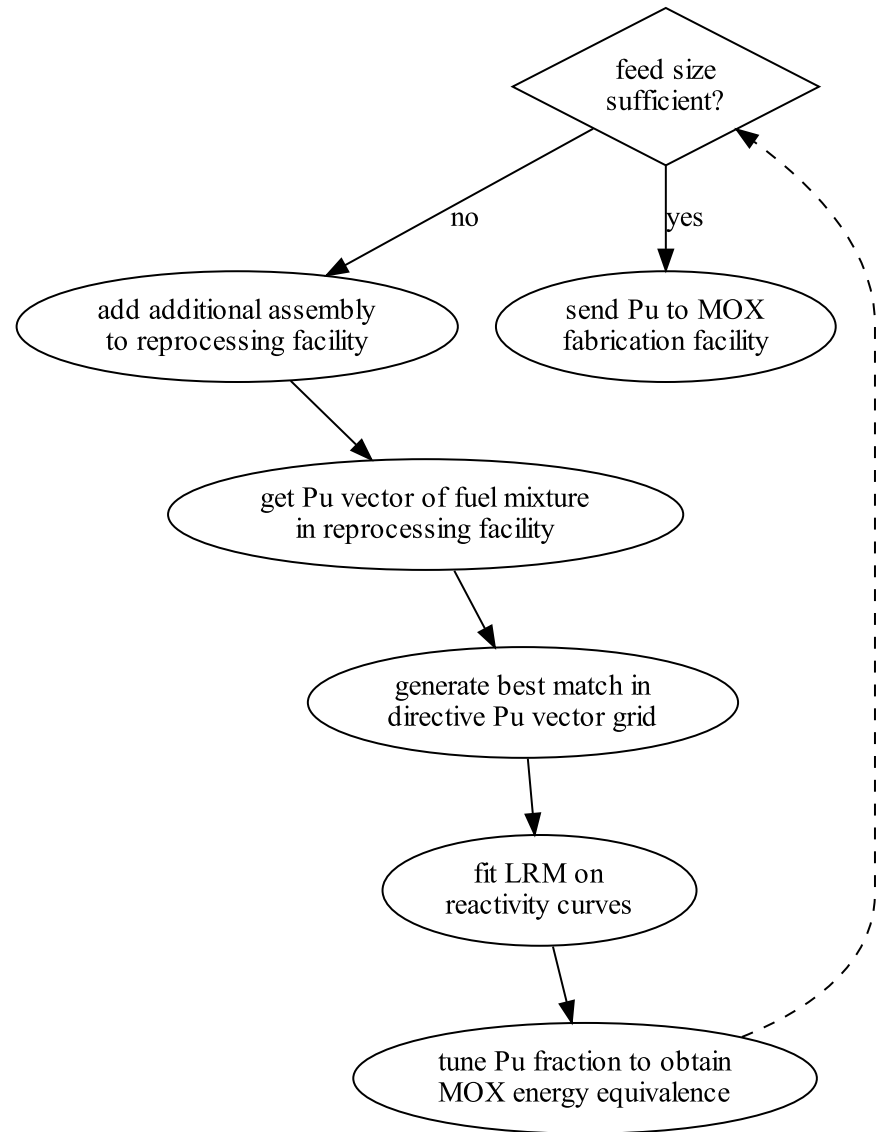

Fig. 5. Process flow diagram of the MOX equivalence Python code package.

A process flow diagram of the MOX equivalence Python code package is provided in Figure 5 .

\section{Reprocessing of a realistic irradiated fuel stock}

When the decision for spent UOX fuel reprocessing is taken after a long period of once through operating mode, the reprocessing strategy, e.g. FIFO (First In, First Out) or LIFO (Last In, First Out), will be a defining parameter in the evolution of the spent fuel inventory. The choice of reprocessing the coldest, oldest assemblies first, or alternatively, the hottest, newest assemblies first, will determine the number of fuel assemblies needed to meet the required MOX feed size as the $\mathrm{Pu}$ vector will be different in both cases. Consequently the choice of strategy will affect the need for interim storage capacities. This analysis may become very complex as the difference in origin of the spent fuel, the irradiation history, and cooling time all introduce an additional dispersion to the $\mathrm{Pu}$ vector, as can be appreciated from Figure 6.

All time-lines that are provided in the remainder of this section are expressed relative to a reference date $t_{0}$, which defines the starting point for the scenario study, i.e. the start of reprocessing of spent UOX fuel according to a 


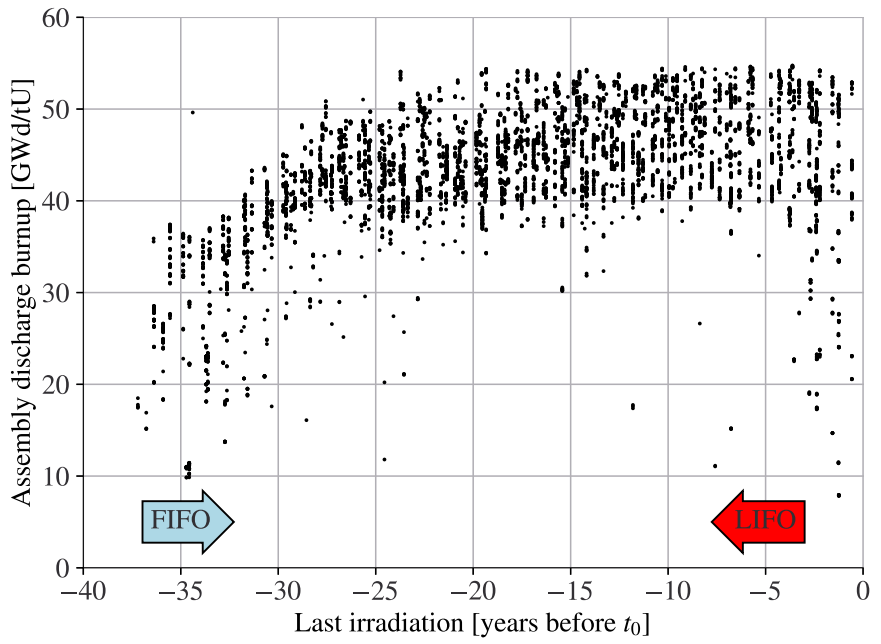

Fig. 6. Fuel assembly discharge burnup for a representative park of nuclear power plants as a function of the time passed between the last irradiation in the reactor core prior to the reference date $t_{0}$.

certain strategy and subsequent irradiation of the MOX fuel in nuclear reactors.

During storage ${ }^{241} \mathrm{Pu}$ decays into ${ }^{241} \mathrm{Am}$, which is then eliminated during reprocessing, but then accumulates back into the fabricated fresh MOX assembly during the waiting period after reprocessing and before core reload. This time-dependent evolution of the $\mathrm{Pu}$ vector results in the energy equivalence capabilities changing over time, and has a strong impact on residual heat and radiation protection aspects during storage and fabrication (e.g. the high energetic alpha decay of ${ }^{238} \mathrm{Pu}$ and ${ }^{241} \mathrm{Am}$ ).

A case study will be presented in this section for which a representative and realistic spent fuel stock will be reprocessed in an ANICCA fuel cycle scenario using the MOX equivalence Python code package. A comparison of four different scenarios will be made, combining FIFO and LIFO strategies with 1.5 or 12 years of delay between reprocessing and core loading. Spent fuel assemblies originate from PWRs fuelled with $\mathrm{UO}_{2}$ fuel issued from enriched natural uranium (ENU), but also enriched reprocessed uranium (ERU). Multi-Pu recycling of spent MOX fuel is not considered in this scenario. Note that the scenarios with 12 years of delay are merely given to illustrate the sensitivities, and may not correspond to a technical reality, especially in the spirit of the assumed just-in-time on-site delivery of MOX fuel.

\subsection{Fuel cycle scenario description}

Energy equivalence will be targeted for a typical 3 GWth PWR operating in 18 month cycles assuming the in-core fuel management characteristics listed in Table 4. The isotopic inventory of the representative stock of spent fuel (characterised by the discharge burnups and cooling times in Fig. 6) is calculated by the ORIGEN-S depletion code at the last core discharge and assuming a realistic irradiation history. Only the fuel region is considered, without structural components. A flow scheme of the material
Table 4. In-core fuel management.

\begin{tabular}{lll}
\hline Parameter & Unit & Value \\
\hline Reactor power & GWth & 3.0 \\
Cycle length & months & 18 \\
Capacity factor & $\%$ & 93 \\
Core heavy metal mass & tHM & 84.7 \\
Fresh feed size & $\#$ FAs & 64 \\
Number of fuel batches & - & 3 \\
Average assembly discharge burnup & $\mathrm{GWd} / \mathrm{tHM}$ & 44.1 \\
UOX enrichment & $\%^{235} \mathrm{U}$ & 4.3 \\
MOX support enrichment & $\%^{235} \mathrm{U}$ & 0.25 \\
MOX/UOX ratio & - & $1 / 4$ \\
\hline
\end{tabular}

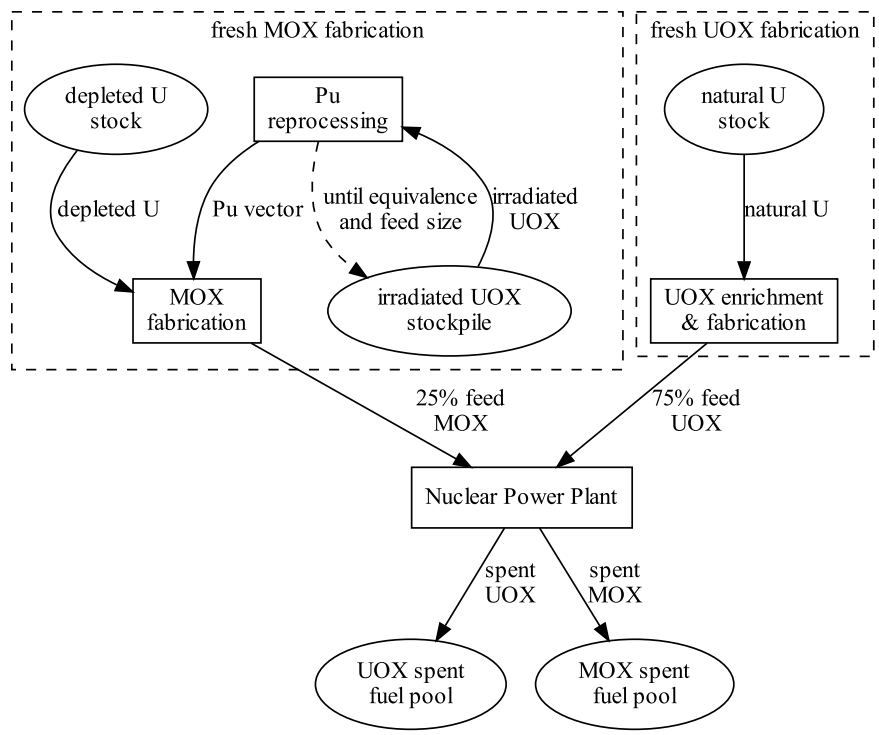

Fig. 7. Spent UOX reprocessing scenario for ANICCA.

transfers in the fuel scenario is presented in Figure 7. The fresh feed consists of $75 \%$ enriched natural uranium (ENU) UOX fuel assemblies with an average enrichment of $4.3 \%{ }^{235} \mathrm{U}$, accounting for the reduced ${ }^{235} \mathrm{U}$ support enrichment in burnable poison rods. The complementary $25 \%$ fresh feed are MOX fuel assemblies with a support enrichment of $0.25 \%{ }^{235} \mathrm{U}$ originating from a depleted $\mathrm{U}$ stock resulting from the tails of the enrichment process. The fabrication of a single MOX assembly will typically require in the order of 10 spent UOX fuel assemblies, depending on the $\mathrm{Pu}$ vector quality and the $\mathrm{Pu}$ mass available in each spent UOX assembly selected for reprocessing. The extraction of spent UOX assemblies is done according to a user-defined sequence (restricted to FIFO or LIFO in this work) following the scheme in Figure 5 in order to fulfil the equivalence objective at core reload. This means that for every cycle 16 MOX fuel assemblies (for a total feed size of 64 fresh fuel assemblies) need to be delivered on-site assuming just-in-time logistics. 


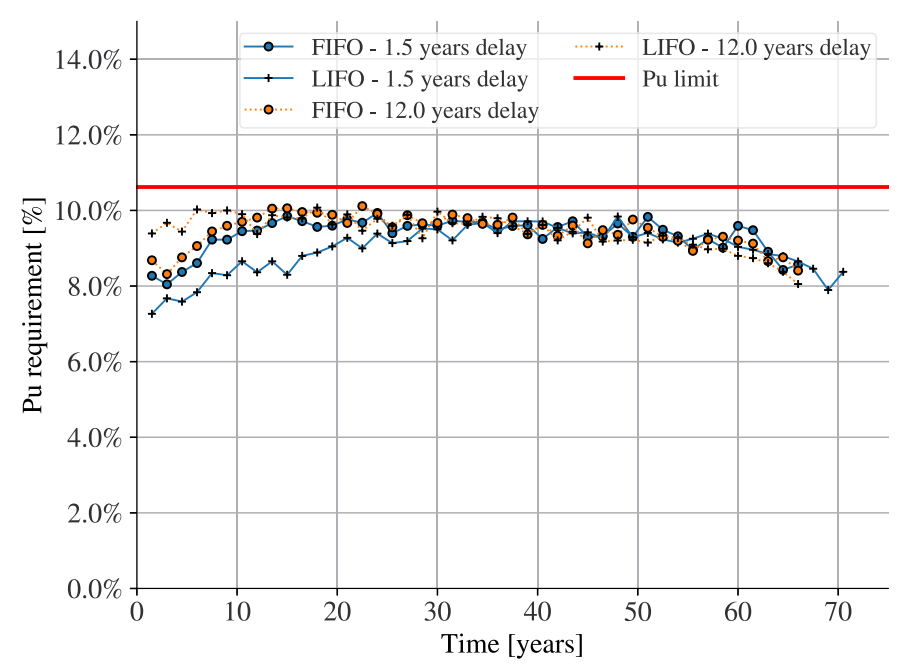

Fig. 8. The $\mathrm{Pu}$ fraction required to meet the energy equivalence for every reload cycle as a function of time passed since the reference date $t_{0}$ using the available irradiated UOX fuel coming out of the stockpile.

\subsection{Results}

The evolution of the $\mathrm{Pu}$ vector for the FIFO and LIFO strategies assuming 1.5 years of delay between reprocessing and core reload is given in Figure 1. A LIFO strategy clearly results in a more dynamic evolution of the $\mathrm{Pu}$ vector over time due to the ${ }^{241} \mathrm{Pu}$ still present in the recently irradiated fuel decaying into ${ }^{241} \mathrm{Am}$. This makes the LIFO strategy less robust in case of unexpected events, because there will be a rapid loss of equivalence in case the assumed reference date for core reload is no longer respected.

The maximum $\mathrm{Pu}$ content during the fabrication of MOX fuel is limited to $12 \%$ as higher $\mathrm{Pu}$ contents could lead to possible criticality and neutronic (positive void coefficient) concerns. In the studied fuel cycle scenario $25 \%$ of the core is uniformly loaded with MOX assemblies whereas for the remaining assemblies enriched $\mathrm{UO}_{2}$ is used. This is done to avoid licensing and safety issues related to e.g. increased neutron absorption in $\mathrm{Pu}$, lower thermal conductivity and increased fission gas release [8]. Consequently the MOX assemblies are mainly surrounded by $\mathrm{UO}_{2}$ assemblies. In order to obtain a more flat power distribution at the boundaries between a MOX and a UOX assembly, the peripheral fuel pins contain less $\mathrm{Pu}$. Accounting for this radial zoning of the $\mathrm{Pu}$ in the fuel rods, the average $\mathrm{Pu}$ content is limited to $10.6 \%$ in order to respect the $\mathrm{Pu}$ limit of $12 \%$ for the inner fuel rods of the considered MOX assembly design [9]. On Figure 8 it can be seen that this $\mathrm{Pu}$ limit is respected for all reprocessing strategies. The FIFO strategy is practically insensitive to the delay after reprocessing, while for the LIFO strategy the $\mathrm{Pu}$ requirements are clearly reduced if the MOX fuel is loaded shortly after $\mathrm{Pu}$ reprocessing. The $\mathrm{x}$-axis on Figure 8 and next indicates the time after the assumed first reprocessing at $t_{0}$, followed by the fabrication of 16 MOX assemblies (25\% feed size) every 18 months.

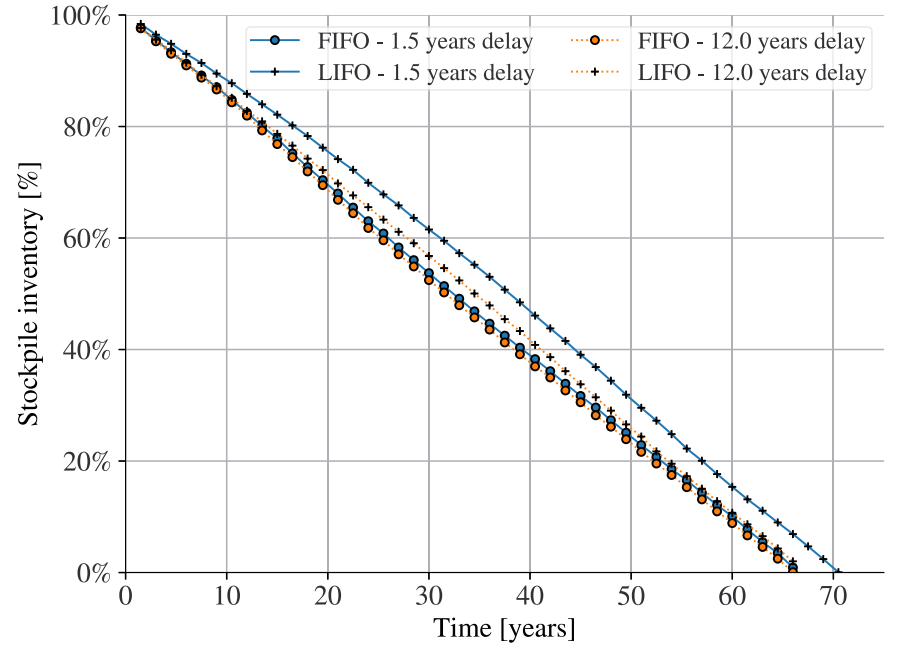

Fig. 9. Fraction of the irradiated UOX assemblies remaining in the stockpile for every reload cycle as a function of time passed since the reference date $t_{0}$.

The occupancy rate of the spent fuel inventory is given in Figure 9 following the different reprocessing strategies. LIFO with a short delay is less demanding in terms of reprocessing efforts (see also Fig. 8) because less spent UOX fuel is needed for MOX fabrication, but this also means that the inventory is evacuated at a lower pace. For FIFO (1.5 years delay) and FIFO/LIFO (12 years delay) the time evolution is rather similar. Depending on the economical conditions related to MOX fuel fabrication and spent fuel storage, either the choice for LIFO (lower reprocessing effort) or FIFO (accelerated reduction of the spent fuel inventory) could become more interesting.

As can be observed on Figure 10, LIFO strategies are more beneficial in terms of heat load removal from the spent fuel inventory as the hottest assemblies are evacuated first, even though its occupancy remains higher than FIFO at all times. Consequently, there is a possible impact regarding radiation protection in the $\mathrm{Pu}$ reprocessing facility: LIFO strategies will initially result in a higher heat load and radio-toxicity in the vitrified waste.

The above results can be used to assess the capacity dimensioning of an interim spent fuel storage building when integrated into a more complex scenario. Suppose a gradual phase-out of a nuclear reactor fleet while simultaneously transitioning into a partial UOX/MOX operation:

- gradual phase-out of all but two PWRs between $t_{0}$ and $t_{0}+6$ years;

- one remaining PWR continues UOX operation until $t_{0}+13.5$ years;

- the other remaining PWR transitions at $t_{0}$ into one of the following scenarios:

- $25 \%$ MOX feed - FIFO reprocessing strategy with 1.5 years delay between reprocessing and core loading;

- $25 \%$ MOX feed - LIFO reprocessing strategy with 1.5 years delay between reprocessing and core loading; 


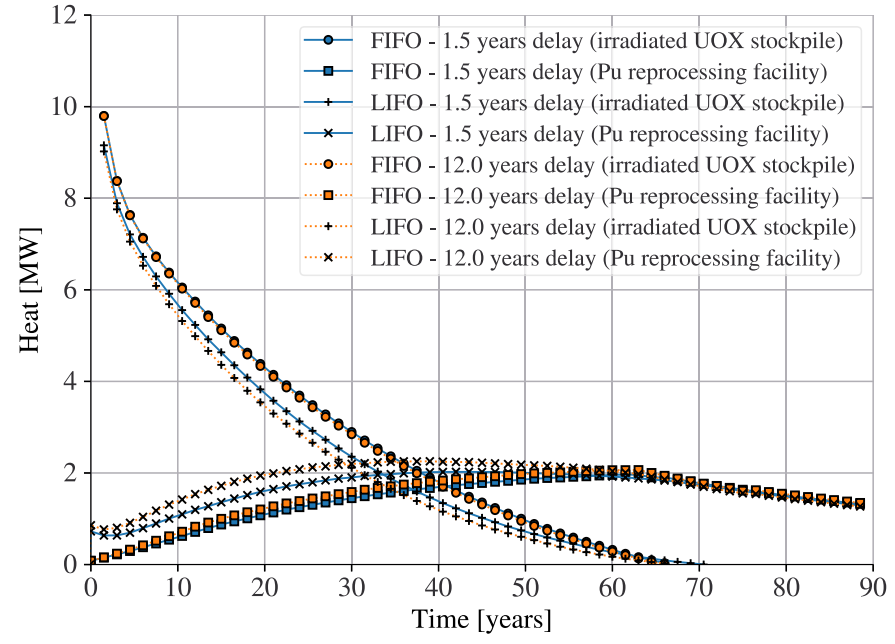

Fig. 10. The time evolution of the heat in the front-end of the fuel cycle scenario (irradiated UOX stockpile and $\mathrm{Pu}$ reprocessing facility) for every reload cycle as a function of time passed since the reference date $t_{0}$.

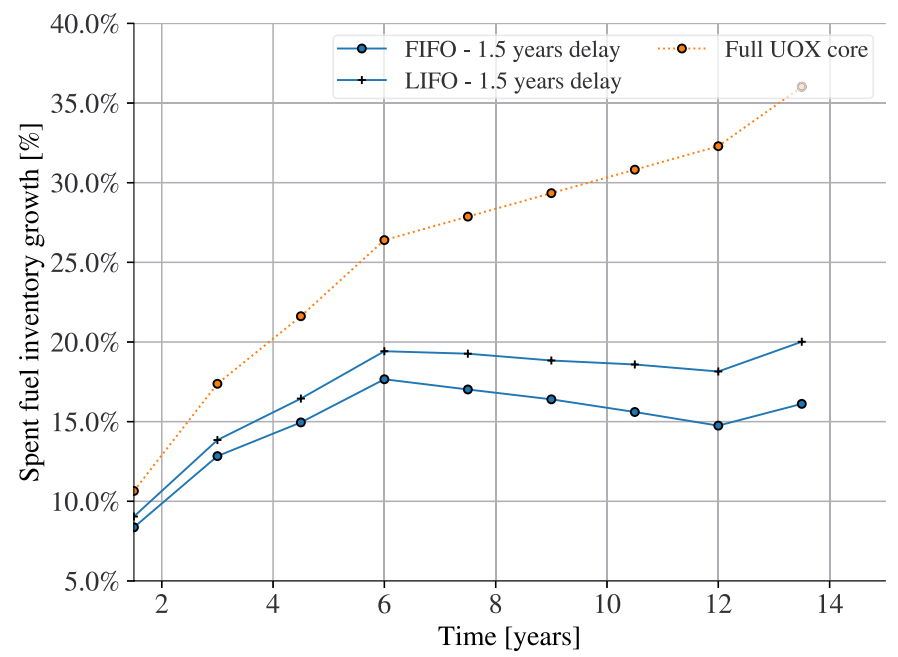

Fig. 11. On-site spent fuel inventory for different transition strategies after a phase-out of a nuclear reactor fleet as a function of time passed since the reference date $t_{0}$.

- full UOX core (as before).

On Figure 11 the difference in impact on the on-site spent fuel inventory can be observed: a transition to MOX for a single PWR can result in a reduced inventory growth of +18 to $20 \%$ instead of $+36 \%$. This shows that a partial transition to a closed MOX cycle can already be beneficial regarding capacity dimensioning of the interim storage building even for a relatively short period of operation. The increase at the end of the scenario is due to the unloading of the entire reactor core at once.

\section{Conclusion}

The fuel cycle analysis tool ANICCA (SCK CEN) has been extended with a MOX equivalence Python code package (Tractebel Engie) to allow an on-line calculation of the $\mathrm{Pu}$ content requirements in MOX fuel fabrication to obtain energy equivalence for different types of in-core fuel management. The methodology encompasses a determination of the reactivity evolution utilising a directive $\mathrm{Pu}$ vector grid, which constitutes the physically accessible space of $\mathrm{Pu}$ vectors, and the application of the Linear Reactivity Model (LRM) to tune the Pu fractions in the MOX fuel.

The capabilities of the MOX equivalence Python code package were demonstrated using a gradual phase-out and transitional fuel cycle scenario in which an inventory of spent UOX fuel assemblies was reprocessed into MOX fuel assuming either a FIFO (First In, First Out) or LIFO (Last In, First Out) strategy. The best choice of scenario clearly depends on the specific needs: LIFO results in reduced reprocessing efforts due to the need for less spent UOX assemblies for the same energetic content in the MOX fuel, while FIFO reduces the storage facility requirements due to an accelerated emptying of the spent fuel pools. The exercise needs to be done for each specific case as the results depend on storage constraints, in-core fuel management, equivalence objectives, acceptable MOX fraction, etc. It is very attractive to think about and optimise it.

The authors would like to acknowledge the contribution of M. Vanderhaegen and C. Schneidesch (Tractebel Engie, Belgium) and I. Merino Rodríguez (Universidad Católica del Maule, UCM, Chile).

\section{Author contribution statement}

All the authors were involved in the preparation of the manuscript. All the authors have read and approved the final manuscript.

\section{References}

1. I. Merino Rodríguez, A. Hernández-Solís, N. Messaoudi, G. Van den Eynde, The nuclear fuel cycle code ANICCA: Verification and a case study for the phase out of Belgian nuclear power with minor actinide transmutation. Nucl. Eng. Technol. 52, 2274-2284 (2020)

2. B.A. Lindley, T.D. Newton, J.G. Hosking, P.N. Smith, D.J. Powney, B. Tollit, P.J. Smith, Release of WIMS10: a versatile reactor physics code for thermal and fast systems, in Proceedings of ICAPP, pages 1793-1801, Nice (France), May 2015

3. M.A. Kellett, O. Bersillon, R.W. Mills, The JEFF-3.1/3.1.1 radioactive decay data and fission yields sub-libraries. Technical report, Nuclear Energy Agency, OECD, 2009.

4. A. Stankovskiy, G. Van den Eynde, Advanced method for calculations of core burn-up, activation of structural materials, and spallation products accumulation in accelerator-driven systems. Sci. Technol. Nucl. Instal. 2012 (2012)

5. K. Govers, D. Boulanger, K. Meert, G. Leinders, M. Verwerft, Characterization of Belgian spent fuel assemblies. Technical Report 1142, SCK CEN, Boeretang 200, Mol (Belgium), April 2019 
6. G. Krivtchik, P. Blaise, C. Coquelet-Pascal, Artificial neural network surrogate development of equivalence models for nuclear data uncertainty propagation in scenario studies. EPJ Nucl. Sci. Technolog. 3, 22 (2017)

7. A.R. Baker, R.W. Ross, Comparison of the value of plutonium and uranium isotopes in fast reactors. In Proc. Conf. Breeding, Economics and Safety in Large Fast
Breeder Reactors (Argonne National Laboratory, 1963), pp. 329-364, ANL-6792

8. Nuclear Decommissioning Authority, NDA plutonium options, Technical report, NDA, August 2008

9. K. McCoy, MOX project: Codes \& methods development, operational performance of WG MOX fuel, in $M O X$ Benchmarking Overview Meeting, Rockville, Md, October (2012)

Cite this article as: Bart Vermeeren, Hubert Druenne, Development of a MOX equivalence Python code package for ANICCA, EPJ Nuclear Sci. Technol. 7, 25 (2021) 